\title{
A narrativa estilhaçada em Assim na terra, de Luiz Sérgio Metz
}

\author{
Claudia Lorena Vouto da Fonseca *
}

\begin{abstract}
Resumo
Este estudo analisa como se dá a relação entre textos, o jogo intertextual em Assim na terra, do sulriograndense Luiz Sérgio Metz, e como as relações que se estabelecem entre diferentes textos estruturam essa narrativa, a qual se constitui a partir do fragmento, da referência e da citação, em suma, da Biblioteca. Inserindo o autor na linhagem dos autores-críticos, explicitamos as relações estabelecidas pelo autor com seus modelos: em especial Jorge Luis Borges, Vicente Huidobro, Octávio Paz e Aureliano de Figueiredo Pinto. Referimo-nos, aqui, ao diálogo que se estabelece entre autores latinoamericanos, especialmente aqueles que, ao mesmo tempo em que produziram literatura, pensaram o fazer literário e, consequentemente, seu próprio lugar no mundo. Próximos, além de uma determinada atividade criadora, esses autores compartilham uma história, uma cultura e um determinado espaço - o mesmo locus de enunciação, o qual não considera, necessariamente, limites políticos, ou, fronteiras.
\end{abstract}

Palavras-chave: Luiz Sérgio Metz. Assim na terra. Jogo intertextual. Biblioteca. Literatura latinoamericana.

Onde estão os fragmentos desse enredo estilhaçado, sem sujeito, sem objeto, mas cada vez mais vivo e real e estranho?

(L.S.Metz)

A literatura não pode ser dissociada das outras áreas do conhecimento, sobretudo aqueles que se referem à área das Ciências Humanas. Também não podemos, igualmente, pensar a literatura dissociada do contexto de sua produção, embora possamos pensá-la inserida em diversos contextos, ou seja: devemos pensar onde, quando e quem a produziu, além de pensar esses aspectos em relação, ainda, a sua recepção. No caso deste estudo, esses são princípios que o norteiam, bem como o conhecimento de que não há como ignorar as relações que se estabelecem entre as nações e povos - e mais que

* Universidade Federal de Pelotas - UFPel. 
nações, regiões - no espaço latino-americano, relações que, de certa forma apagam fronteiras políticas.

Mais do que uma teoria, a intertextualidade também desconhece fronteiras, sobretudo se considerarmos as relações que se estabelecem entre autores e suas respectivas obras, não apenas de forma mais abrangente, mas mais especifica: neste caso, autores que compartilham o mesmo locus de enunciação. Próximos, além de uma determinada atividade criadora, compartilham uma história, uma cultura e um determinado espaço - o qual não considera, necessariamente, limites políticos. Referimo-nos, aqui, ao diálogo que se estabelece entre autores latino-americanos, especialmente aqueles que, ao mesmo tempo em que produziram literatura, pensaram o fazer literário e, consequentemente, seu próprio lugar no mundo.

Falamos de autores como Jorge Luis Borges, Mario Benedetti, Octavio Paz, Julio Cortázar, Ángel Rama e Antonio Candido, por exemplo. Falamos do pensamento latinoamericano, intimamente relacionado ao fazer literário, e do imbricamento das vozes que falam deste lugar. Alguns desses autores exercem a crítica literária, outros são críticos escritores, outros, ainda, escritores-críticos, na acepção de Leyla Perrone-Moisés, esses últimos, aqueles que exercem a crítica a partir de sua produção literária, no interior mesmo dessa produção. Um ponto em comum entre esses autores é que seu objeto de investigação é invariavelmente o mesmo, além de citarem-se entre si.

Naquilo que tange a esses questionamentos, a obra que deu origem a estes, e que desencadeou a investigação é Assim na terra, do autor gaúcho Luiz Sérgio Metz, publicada em 1995, contemporânea, portanto. Nela, um sujeito busca seu lugar num contexto que se transforma rapidamente. Essa busca é de pertencimento, de identidade. Por esse motivo, o autor constrói sua obra sobre referências e sobre a memória. É evidente o diálogo com Borges, Eliot, Mallarmé, Huidobro, Alcides Maya, Cyro Martins, Cortázar, Hernandez, Guiraldes, Rulfo, Octavio Paz, Flaubert, Goethe, Uslar Pietri, Kafka e Aureliano de Figueiredo Pinto, para ficarmos apenas nas relações de primeiro grau, percebidas à flor do texto, dessa intertextualidade que não é apenas citação, mas estrutura narrativa. Percebemos que o intertexto e o jogo que se estabelece com a Biblioteca são suas características dominantes.

Um longo caminho foi percorrido no campo dos estudos de literatura até que, o que hoje é consenso acerca da natureza da obra literária, chegasse a sê-lo, ou seja, toda obra literária é, em diferentes medidas, intertextual. A relação entre livros ou, entre Bibliotecas, é objeto de investigação não apenas 
de muitos estudiosos, mas sobretudo dos próprios autores, que teorizaram, e teorizam, sobre a escritura: a sua própria e, de maneira geral, sobre o fazer literatura, buscando compreender suas formas e as relações que se estabelecem entre textos e autores. Alguns desses autores tornam-se referência: Jorge Luis Borges, Stephane Mallarmé, T.S.Eliot, Goethe, Octavio Paz. Trata-se de uma rede, na verdade, de autores e textos que se tecem a partir da palavra por eles proferida. Faz parte dessa estirpe de autores-críticos, unindo crítica e escritura, o gaúcho Luiz Sérgio Metz.

Autor de uma produção pouco extensa, porém significativa, não apenas para as letras gaúchas, Metz, a exemplo dos autores que se tornaram referência em sua concepção de escritura, por ele ressimbolizados, filia-se, a essa linhagem, em especial através de seu único romance, objeto desta análise. Em Assim na terra, o autor dialoga não apenas com outras obras, mas com estéticas, resultado de suas leituras desses autores e dos processos de criação explicitados por estes. Destaque para o diálogo com Borges e com Eliot, embora esse diálogo se estenda a Mallarmé, por exemplo, além de Cortazar, Paz e Huidobro. Trava-se, na obra, uma discussão metaliterária no interior do universo ficcional, configurando-se em um dos melhores exemplos dessa intertextualidade, como a concebemos nos dias de hoje: intertextualidade como invenção, forma de tecer, como prática, exercício intertextual.

Quanto à análise da obra, destacamos alguns aspectos. Entre eles, a singularidade de sua estrutura. Assim na terra começa e termina com um ciclo de estações. $\mathrm{O} 1^{\circ}$ ciclo constitui-se em memórias fragmentárias, que situam o espaço: O Sul físico e psicológico/mítico e, nesse caso, pretérito. Já o $2^{\circ}$ ciclo aponta para o futuro, são memórias, mas são posteriores às do primeiro ciclo. Expressa, ainda, certo temor a esse futuro, desencanto e falta de perspectivas pelo que se anuncia. Constituindo-se em moldura para o narrado e, mais do que isso, em quadros, os ciclos têm uma função importante na economia narrativa, pois são determinantes para a possibilidade de ocorrência do que se narrou, assegurando-lhe verossimilhança: no interior dessa moldura estão um tempo e um espaço possíveis apenas enquanto tempo e espaço delimitados. A função das molduras em Assim na terra é semelhante àquela que caracteriza a de uma pintura, ou seja, além de delimitar, cumpre uma função estética, arrematando e valorizando o quadro. Não por acaso, o discurso presente no ciclo de estações, sobretudo no primeiro deles, é extremadamente pictórico.

No interior dessa espécie de moldura, constituída pelos ciclos de estações, situam-se os fatos narrados, começando e terminando pelo inverno. Esse 
espaço e tempo míticos, espaço e tempo do verbo, território da palavra articulada, adentra o protagonista de Assim na terra, explicitando as relações dialógicas que a obra estabelece com outros autores e obras, com outros gêneros e concepções de escritura, e com as formas como estas se dão. Esse corpo da narrativa se divide em três capítulos, que compreendem nascimento, infância, adolescência e amadurecimento do narrador protagonista, os quais reproduzem, e correspondem, ao percurso dantesco pelo inferno, purgatório e paraíso. Em cada um desses capítulos um pacto. O capítulo um trata da partida do narrador, seu percurso à margem das cidades, observando o espaço do mundo rural sendo substituído pelo do urbano, inventariando, rememorando e anotando tudo em uma caderneta. Sua trajetória é descendente e é constituída de episódios que preparam o encontro com a personagem Gomercindo, responsável pela experiência fundamental pela qual passa o protagonista, iniciado por essa personagem. Já o capítulo dois trata do período em que o narrador permanece em companhia de Gomercindo, no Pensário, espécie pouco convencional de construção que o narrador chama de galpão. Por fim, o terceiro capítulo trata da segunda partida do narrador, agora acompanhado por Gomercindo, com o qual pactua.

A narrativa transcorre, como dissemos, em um espaço que é mítico, mas que é, ao mesmo tempo, um espaço que poderíamos chamar de rural, mas esse mundo rural em Assim na terra é a origem, a própria identidade. Na verdade, uma espécie de margem, fronteira entre o rural e o periférico. O urbano é visto como ruim, mas inevitável, a busca é a de solução para esse impasse: sair da margem. O urbano vem preenchendo todos os espaços e seduzindo todo um povo. Trata-se de um mundo rural que vem assimilando a modernidade. Mesmo os protagonistas, o narrador e seu guia, já foram "contaminados", por mais que queiram preservar o mundo/sistema original, pois a erudição, a exposição ao pensamento, já os faz híbridos, ou seres em metamorfose, em processo obrigatório de mimetização. Eles têm consciência da modernidade, e o quanto há de inevitável nessa situação. O espaço se modifica e o sujeito sofre as mudanças que se estão operando. O tempo aponta para um futuro em que a técnica dita as regras do viver, e há a constatação da impossibilidade de deter esse avanço, ou o ritmo das mudanças, em um mundo que se torna cada vez menor e padronizado. A terra amarga uma espécie de esterilidade e as relações que se estabelecem entre os homens tornam-se mais superficiais, regidas pelo individualismo. Sensação de incomunicabilidade. Os protagonistas rejeitam e buscam uma forma de subverter essa ordem, uma alternativa, uma forma de 
preservação que não seja a cristalização ou fossilização. Por isso a busca de um refúgio, que pode ser o lugar e o tempo do mito, esse entre-lugar, o Sul.

Luiz Sérgio Metz vai se valer na composição de sua obra, da herança da gauchesca platina do modernismo (hispânico), do esteticismo amplamente concebido e do subjetivismo (por sua vez herança do Romantismo), que influenciaram as vanguardas que sucederam ao modernismo e que ocorrem paralelamente ao movimento regionalista. Pode-se perceber uma proximidade muito maior com a literatura platina que com brasileira, no sentido nacional, em Assim na terra. A menção a Flaubert, lado a lado com Guiraldes, é reveladora dessa presença dos modelos da literatura do pampa: não há portugueses citados em Assim na terra, deixando claro a que sistema pertence, a qual sistema se filia.

A relação estreita do autor com a obra de Jorge Luis Borges e o diálogo que Luiz Sérgio Metz estabelece com o argentino são decisivos para a produção de Assim na terra. De Borges o autor empresta um espaço, temas, símbolos e uma concepção de tempo, mítico, circular, com portas que se abrem deixando que os tempos se tornem concomitantes, que se sobreponham. Porém, do autor argentino, Metz empresta também um projeto, que é o de uma origem, uma inserção em um sistema, uma filiação. O autor gaúcho faz com Aureliano o que Borges faz com Carriego, seus projetos são análogos, e diríamos que não se trata de uma casualidade. Borges elege Carriego como pai e símbolo.

Em seu plano recuperador, Borges salva Carriego e se coloca nas orillas, se apropria de um universo ao qual ele só tinha acesso mediado pelas grades do jardim de sua casa, no mesmo bairro de Palermo, que era o universo de Carriego, o poeta menor, popular e subliterário. "El hombre que descubrió las posibilidades literarias de los decaídos y miserables suburbios de la ciudad, [...] el poeta que mitologizó el Palermo de fines del siglo XIX" (PAULS; HELFT, 2000, p.17). Beatriz Sarlo afirma que não tinha como Borges não se interessar por Carriego, pois

ali, talvez de maneira desajeitada, estava uma matéria que os escritores da época julgaram marginal. Quando, na primeira década do século, Lugones e o modernismo ocupavam o centro literário, Carriego era justamente a margem. [...] Num país marginal, Carriego tomara lugar à margem da margem: à margem de Lugones e do modernismo, que Carriego quis imitar mas que abandonou para escrever os poemas que Borges situa em sua própria origem poética.

(SARLO, 2008, p. 51-52 - destaques da autora). 
Por meio de Carriego e das orillas, Borges funda sua literatura em oposição aos dois tons dominantes, segundo a autora, o que significa uma ruptura com Lugones e com o modernismo, respondendo assim à pergunta sobre como escrever depois de Lugones e contra ele. (SARLO, op. cit., p.57). Dessa forma, buscando em Carriego apenas o que lhe interessava, lendo-o de viés, Borges subverte a hierarquia, deslocando Lugones, fazendo da literatura marginal de Carriego o princípio de sua própria literatura. É no poeta menor da antologia que Borges funda sua originalidade.

¿Dónde está la memoria de los días que fueron tuyos en la tierra, y tejieron dicha y dolor y fueron para ti el universo? (BORGES, 1974, p. 8)

Já o autor gaúcho elabora, intencionalmente, seu próprio plano recuperador de um poeta considerado menor/marginal na literatura do Rio Grande do Sul, estabelecendo, ele também, sua filiação literária, negando Cyro Martins como pai literário, o que seria o mais lógico. A diferença, nesse caso, é que se em Borges a biografia de Carriego é já parte do projeto, em Metz a biografia que ele prepara para Aureliano é que faz com que o autor vislumbre essa possibilidade, que só irá se concretizar em Assim na terra. A biografia de Aureliano, cujo objetivo primeiro era o de realmente, e tão somente, biografrar um autor gaúcho, desperta e fomenta o projeto literário de Metz. É nela que encontramos, já, a motivação do autor ao produzir sua obra, bem como o vislumbre da solução por ele encontrada para que seu projeto se concretizasse: fazer um Aureliano de Figueiredo Pinto. Nela, Metz afirma que pode fazer um Aureliano:

Falo de um Aureliano grande, que lia para ser grande, que se preocupava como homem grande. Por isso o comparo a homens grandes. Enormes. Imortais. Posso fazer um Aureliano imaginário ou real, posso fazer os dois. Porque a mim é dado esse direito, a todos nós é dado ressaltar as qualidades daquilo que queremos. Porque nós somos homens e somente nós fazemos a história. E eu faço assim e não faço somente porque quero. Mas porque necessito. (METZ, 1986, p. 37 - destaques nossos).

Além disso, cogita Metz: 'Se o 'velho' desse as mãos ao 'vivo', ou viceversa, e saíssem pelo mundo sem contradições, aconteceria isso: 1986, 1985, 1984... A terra giraria ao contrário do que lhe dá movimento." (METZ, 1986, p. 
37 - destaques do autor). Tinha dúvidas quanto à viabilidade desse projeto, se poderia realizá-lo:

A geológica coluna ou lâmina do tempo calcada nas calçadas missioneiras the abriria espaço para passar? O espaço confabularia com o tempo para juntos talharem Aureliano contra o céu de nuvens vermelhas, e seu passo marcaria novamente a terra dos guaranis? (METZ, 1986, p. 58).

Portanto a obra é o projeto de "salvar" Aureliano, desejo que este manifestou no poema "Este livro":
Resta esperança e consolo:
- Um dia algum índio bueno, crioulo, mas bem crioulo! ao ir pitando este rolo no seu rincão, mui sereno, verá que este trançador não é nenhum cajetilha (...) Mas Chiru ao tempo curtido com olhos de ver no escuro
(...)
Talvez alguma patrícia padrão de gaúcho valor, possa dizer a esta história:
- Se não me falha a memória eu conheci este cantor... (PINTO, 1997, p. 31-32).

A personagem Gomercindo é uma imagem, um simulacro de Aureliano, que Luiz Sérgio Metz cria e o narrador encontra numa vala, trazendo-o de volta para que este lhe forneça os "mandamentos", as instruções para a construção da obra que vai salvá-lo, a sua obra definitiva, síntese, que vai unir autor e biblioteca do autor e dando ao pai literário uma morte "digna", segundo o imaginário gaúcho, a morte desejada, que se não é em duelo, como em "O sul”, de Borges, é cavalgada "cega". Por esse motivo as molduras em Assim na terra, que cercam e guardam o tempo suspenso, o período em que se resgata um homem e seu tempo, no espaço do inverno em um Sul mítico. O mundo a que o autor/ narrador traz Aureliano de volta é um mundo do tempo e do espaço de Borges, tempo e espaço da ficção e do delírio, da febre, para que ao final ele se vá "dignamente", dando sentido também à sua vida e obra. 
T.S.Eliot, por sua vez, empresta ao autor de Assim na terra, aquilo que Borges não poderia lhe fornecer: o ritmo, que configura a segunda voz narrativa, lírica, que faz com que essa obra essencialmente masculina, possa conter também seu elemento complementar, o feminino. Considerado um escritor frio, demasiado intelectual, afirma Borges: "Não me propus ser um poeta. Apenas um homem de letras inteiro: um homem que conversa, não um que canta...”. Descontada a conhecida "modéstia" borgeana, em tudo adequada à sua personalidade literária, pode-se dizer que esse é o motivo pelo qual Luiz Sergio Metz, ele próprio um cantor, elege Eliot para com ele dialogar cantando. Sabemos, ainda, que também Aureliano de Figueiredo Pinto se auto-intitulava um cantor. O diálogo com T.S.Eliot se dá também em termos de conteúdo, além da forma, mas não se trata de citação explícita, e sim do aproveitamento de temas, entre os quais há uma equivalência. São imagens literárias que o autor toma de empréstimo, da obra de Eliot, especificamente.

Já o diálogo entre Luiz Sérgio Metz e Octavio Paz se dá essencialmente no plano teórico-crítico. $\mathrm{O}$ autor gaúcho compartilha com o mexicano de sua concepção de escritura, a qual se percebe disseminada pela obra de Metz que analisamos. Constata-se a "aplicação", pelo autor gaúcho, de pressupostos contidos na obra crítica de Paz, na elaboração de sua própria obra. Por exemplo, não há uma circularidade tradicional, se assim podemos denominar, em Assim na terra. Há, sim, uma espécie de circularidade, como já dito, no sentido de que o princípio da trajetória do protagonista esclarece seu fim e é esclarecido por este: no meu fim o meu princípio, no meu princípio meu fim, referência a Eliot e um leitmotiv em Assim na terra. O ciclo de estações do final é que dá origem ao primeiro ciclo e ao narrado. Mas em sua totalidade, a obra não é circular, ela não se fecha em si mesma, pois há uma abertura em direção ao futuro. A esse respeito, lemos em Octavio Paz:

A figura geométrica que simboliza a prosa é a linha: reta, sinuosa, espiralada, ziguezagueante, mas sempre para diante e com uma meta precisa. (...) O poema, pelo contrário, apresentase como um círculo ou uma esfera - algo que se fecha sobre si mesmo, universo auto-suficiente no qual o fim é também um princípio que volta, se repete e se recria. (PAZ, 1982, p. 83/84).

O crítico mexicano afirma que, nas obras em que "as frases não se sucedem obedecendo a uma ordem conceitual ou narrativa, mas são presididas pelas leis da imagem e do ritmo" (PAZ, 1982, p. 87), a prosa se nega a si mesma, o que faria delas verdadeiros poemas. Dessa forma, o autor chama de poemas obras 
como Alice no país das maravilhas, de Lewis Carroll, e "O jardim dos senderos que se bifurcam”, de Jorge Luís Borges. Mas Octavio Paz diz também, e nesse caso parece prever o que virá, que "as obras do tempo que nasce não estarão regidas pela idéia da sucessão linear e sim pela idéia de combinação: conjunção, dispersão e reunião de linguagens, espaços e tempos." (PAZ, 1972, p. 137).

Assim na terra comprova o que se esboça, para Octavio Paz à época, uma idéia de combinação. Na obra do autor gaúcho estão presentes, por exemplo, as duas figuras, a linha e o círculo, pois, embora impregnada de lirismo, a prosa não pode ser negada, é de prosa que estamos falando. Assim na terra é uma narrativa, é também linha para diante, abertura para o que está por se fazer, e que poderá se constituir de novas circularidades, não se sabe, com intervalos de suspensão temporal, talvez, premência do sonho. Ou uma regressão? Pois a indefinição e a impossibilidade de previsão, somadas ao quadro geral do presente, geram angústia no narrador. No entanto, o rumo é em frente, preservando, da forma que for possível, a origem.

Quanto ao diálogo estabelecido com Vicente Huidobro, podemos dizer que este se dá tanto ao nível teórico quanto literário. Esse diálogo, vislumbrado apenas a partir de uma despretensiosa e até graciosa alusão ao poeta chileno, faz com que quase não percebamos, a princípio, sua relação com a obra e com o momento específico do protagonista, que prepara sua criação.

Deus te dê Huidobro

Tudo o que me desejares.

(METZ, 1986, p. 57).

Segundo Huidobro: "La primera función del poeta es crear, la segunda, crear, la tercera, crear." (HUIDOBRO, 1990, p.112):

Un poeta debe decir aquellas cosas que nunca se dirían sin él. (...) Los poemas creados adquieren proporciones cosmogónicas. (...) El poema creacionista se compone de imágenes creadas, de situaciones creadas, de conceptos creados; (...) Si para los poetas creacionistas lo que importa es presentar un hecho nuevo, la poesía creacionista se hace traducible y universal, pues los hechos nuevos permanecen idénticos en todas las lenguas." (HUIDOBRO, 1990, p.111-117).

Não podemos esquecer que o período em que viveu e produziu Vicente Huidobro é um período caracterizado pela radicalização das experimentações formais, no que diz respeito às artes em geral, na história literária da América 
Latina. É nesse sentido que Metz dialoga com Huidobro, a partir de sua concepção de criação poética, embora haja também um aproveitamento de temas emprestados do autor chileno.

Por fim, destaque-se que, no que tange às questões relativas à transição/ permanência/atualização do regionalismo ou, da validade ou não da literatura de tema rural nos dias de hoje, fica evidenciado, a partir do estudo de Assim na terra, que essa vertente da literatura, hoje, só tem validade ressimbolizada, a partir de procedimentos autorais, como aqueles de que faz uso Luiz Sérgio Metz na produção de sua narrativa. A leitura de Assim na terra pelo viés da Intertextualidade valoriza a obra, pois faz com que a obra não se configure como regionalista, conservadora, passadista e idílica: o campo "com peão dentro" e, consequentemente, um patrão-ruralista para mandar nele. Reduzir Assim na terra à obra regionalista pura e simples é negar-lhe seu lugar de direito na história da literatura, no cânone da literatura sem fronteiras, pois que ela realiza plenamente, a partir de uma intertextualidade generalizada, a ressimbolização, não apenas de um imaginário regional, mas a de textos e autores da literatura universal.

\begin{abstract}
This article analyzes the intertextual relations between the novel Assim na terra, by Luiz Sérgio Metz and other fictional narratives of Latina America. Explicit relationships are established by the author with Jorge Luis Borges, Vicente Huidobro, Octavio Paz and Aureliano de Figueiredo Pinto. Showing a strong appeal concerning fictional strategies and elaboration, Metz presents a sophisticated narrative structure and innovative fictional exercise.
\end{abstract}

Keywords: Luiz Sérgio Metz. Assim na terra. Intertextualiy. Library. Latinoamerican literature.

Referências

BORGES, Jorge Luís. Obras completas. Buenos Aires: Emecé, 1974. BORGES, Jorge Luís. Obras completas - 1975/1985. Buenos Aires: Emecé, 1989.

CHIAPPINI, Lígia; MARTINS, Maria Helena; PESAVENTO, Sandra Jatahy 
(Orgs). Pampa e cultura. Porto Alegre: Editora da UFRGS/IEL, 2004.

CHIAPPINI, Lígia; MARTINS, Maria Helena. (Orgs.) Cone Sul - fluxos, representações e

percepções. São Paulo: Hucitec, 2006.

ELIOT, Thomas S. Obra completa. Vol I. Poesia. Tradução, introdução e notas de Ivan Junqueira. São Paulo: Arx, 2004.

HUIDOBRO, Vicente. Antología poética. Edición de Hugo Montes. Madrid: Castalia, 1990.

HUIDOBRO, Vicente. Altazor e outros poemas. Edição Bilíngue. Trad. Antonio Risério \& Paulo Cesar Souza. São Paulo: Art Editora, 1991.

MARTINS, Cyro. Visão crítica do Regionalismo. In: MARTINS, Cyro. Sem rumo. $5^{\text {a }}$ ed. Porto Alegre: Movimento, 1997.

MARTINS, Maria Helena (Org.). Fronteiras culturais - Brasil-Uruguai-Argentina. Porto Alegre: Ateliê Editorial, 2002.

METZ, Luiz Sérgio. Aureliano de Figueiredo Pinto. Coleção 'Esses Gaúchos'. Porto Alegre: Tchê!, 1986.

METZ, Luiz Sérgio. Assim na terra. Porto Alegre: Artes \& Ofícios, 1995.

MONTALDO, Graciela. Nacionalismo, regionalismo, identidades. In: MONTALDO, Graciela. Rio de la Plata: Culturas. Actas del quinto congreso internacional del CELC/RP. Paris: Sorbonne-Nouvelle, jul. 1996.

PAULS, Alan; HELFT, Nicolas. El factor Borges - nueve ensayos ilustrados. Buenos Aires: Fondo de Cultura Econômica, 2000.

PAZ, Octávio. O arco e a lira. Tradução de Olga Savary. Rio de Janeiro: Nova Fronteira, 1982.

PERRONE-MOISÉS, Leyla. Texto, crítica, escritura. São Paulo: Ática, 1978. PINTO, Aureliano de Figueiredo. Romances de estância e querência. Porto Alegre: Movimento, 1997.

PIZARRO, Ana. La literatura latinoamericana como proceso. Buenos Aires: Ed. Centro Editor de América Latina, 1985.

PIZARRO, Ana. "Hispanoamérica y Brasil: Encuentros, desencuentros, vací- 
os”. In: PIZARRO, Ana. Acta literatura. 2004, n. 29. Concepción.

SAMOYAULT, Tiphaine. A intertextualidade. Tradução de Sandra Nitrini. São Paulo: Aderaldo e Rothschild, 2008.

SARLO, Beatriz. Jorge Luis Borges, um escritor na periferia. Tradução de Samuel Titan Jr. São Paulo: Iluminuras, 2008. 